Educação a importância de Cr\$ $5.000,00$ arrecadados nas escolas do Estado e que se destinam ao Fundo Nacional de Ensino Primário.

30 - Realiza-se, no Palácio do Comércio, de Fortaleza (Ceará), uma conferência do Dr. Urbano de Almeida, Delegado Reginal do S.E.N.
A.I., sobre as finalidades do ensinei industrial.

30 - Noticia-se que o Departamento de Educação do Estado da Bahia está fazendo distribuir 20.000 livros, 50.000 lápis e 8.000 folhas de cartolina entre escolares da capital $\mathrm{c}$ do interior do Estado.

\title{
INFORMAÇÃO DOS ESTADOS
}

\section{ALAGOAS}

O Diretor do Departamento de Educação do Estado, Padre Medeiros Neto, fêz as seguintes declarações ao " Jornal de Alagoas", de Maceió:

"E' Alagoas, porventura, um Estado onde o ensino primário se encontre desvitalizado? Não. Um Estado que possui 33 municípios e detém 43 grupos-escolares com prédios próprios, se encontra em situação, relativamente privilegiada. Ademais, este número, ainda este ano, será acrescido de dois outros grupos, construídos, técnica e pedagògi-camente. Como noutras unidades da Federação, os nossos grupos tendem a dispor de Biblioteca Infantil, Museu Escolar e de melhor aparelhamento di-dático-escolar. As atividades e instituições auxiliares do ensino já existem: clubes de leitura, cooperativas, caixas escolares, excursões.

Em 19-11, no Instituto Nacional de Estudos Pedagógicos, Alagoas foi o Estado mais bem representado no Curso de Férias que ali se fazia, em combinação com a Associação Brasileira de Educação. Estagiaram, ali, por durante 2 meses, 3 professores primários do Estado. Com estes elementos e com a dedicação do professorado, em geral, se pode fazer e marcar uma época de mais atividade na vida educacional dos grupos escolares.
Foi instalada, na Diretoria da Educação, uma Seção de Pesquisas Pedagógicas. Por intermédio desta seção, pude regularizar o seguinte: divisão do programa em etapas letivas, provas de aplicação (mensalmente), provas seletivas (trimestralmente) e absoluta vigilância no aproveitamento dos alunos. A prova clássica, formalística, cedeu lugar às provas com aplicação de testes escolares e questões objetivas. Destarte, o rendimento escolar deixará de ser aparente para tornar-se real. A promoção será uma questão de mérito. E passará o nosso ensino primário de ônus para compensação moral ao Estado. Ademais. com este processo, se farão as classes selecionadas, que oferecerão oportunidade para a criação dos quadros nivelados, dentro do espírito da renovação educacional".

\section{BAHIA}

Pelo Decreto-lei n. ${ }^{\circ} 15$, de 6 de setembro de 1943, estabeleceu o governo do Estado da Bahia um plano quatrie-nal para a construção e instalação de escolas públicas.

A parte da construção de novos prédios escolares e terminação das construções, que se acham em andamento, coube à Secretaria de Viação e Obras Públicas. Quanto ao que toca à insta- 
lação das escolas ficou incumbido o Departamento do Serviço Público.

Efetivam-se as primeiras providências para a execução do plano referido. $\mathrm{O}$ Departamento do Serviço Público abriu concorrência para aquisição, em grande escala, de móveis escolares. A essa concorrência compareceram três firmas, tendo duas delas propostas aceitas. Por outro lado, grande quantidade de carteiras será também fabricada na Penitenciária, com sensível economia para o Estado e a vantagem de ter em funcionamento as oficinas daquele presídio.

\section{RIO GRANDE DO SUL}

Foi concluído o plano de edificações escolares, cuja execução começou em 1938. O governo do Estado trata da elaboração de outro, que abrangerá construções tanto do ensino primário, como normal e secundário.

O orçamento deste novo plano, segundo o projeto preparado pela Secretaria de Educação será de 15 milhões de cruzeiros.

\section{SANTA CATARINA}

O interventor de Santa Catarina, em recente decreto, criou a Liga Pró-Lín-gua Nacional, destinada a funcionar em núcleos autônomos, em todos os educandários do Estado. Conforme consta do texto do decreto assinado pelo in terventor Nereu Ramos, aos núcleos visarão difundir o espírito de cooperação nas escolas, não só entre o professorado como entre os educandos, com a finalidade de encaminhar a colaboração dos alunos para a maior expansão e maior solidez do espírito nacional. A Liga Pró-Língua Nacional será dirigida pelos próprios alunos, dentre aqueles que possuam capacidade para atender aos seus objetivos. Cada um de seus mem- bros procurará entrar em contato com os que tenham dificuldade de pronúncia, principalmente nas zonas de colonização, procurando corrigir os seus erros. Os núcleos formarão álbuns de assuntos, nacionais, organizarão um calendário patriótico, estabelecerão cooperação nas datas festivas e em horas de arte, mantendo correspondência entre si e com todos quantos se interessem pelas suas atividades.

\section{SÃO PAULO}

A propósito da passagem do terceiro ano de administração do Sr. Interventor Fernando Costa, no Estado de São Paulo, concedeu o Dr. Sebastião Nogueira de Lima, Secretário da Educação e Saúde, nesse Estado, as seguintes declarações à imprensa:

Ensino primário - O ensino primário é e ainda será por muitos anos o nosso grande e fundamental problema.

A porcentagem de analfabetos, ainda é, infelizmente bem elevada. $\mathrm{O}$ número de nossas escolas primárias ainda está muito aquém das necessidades. Não obstante, o número de nossas unidades escolares, isto é, escolas isoladas e classes de grupo escolares, é bem grande e com elas despende o Estado, anualmente, vultosas importâncias. O problema é assaz complexo, mas tem na sua base, a escola. Por ele preocupa-se profundamente o Interventor Federal, Sr. Fernando Costa, no firme desejo de, na medida do possível, combatê-lo eficazmente. Nesse propósito e no desenvolvimento de seu construtivo governo, vai Sua Excelência, em cada ano, criando escolas e grupos escolares, na Capital e no interior. e muitos outros deverá criar. São, a esse respeito, significativos os seguintes dados:

Em 1941, foram criadas 103 escolas e 32 grupos escolares, com 103 classes, 
num total de 206 unidades. No fim de 1941 possuía o Estado 12.554 unidades, compreendidas aí não só as classes de grupos escolares e escolas isoladas de tipo comum como classes de educação infantil, de cursos populares noturnos, de escolas maternais e de experimentais de tipo rural, escolas junto a unidades militares, escolas industriais junto a fábricas c outras que funcionavam junto a instituições particulares.

Funcionaram nesse ano 723 grupos escolares dos quais foram criados, no segundo semestre 24, sendo um localizado na capital.

Em 1942, foram criadas 143 escolas e 24 grupos escolares, com 74 classes, num total de 217 unidades. No fim do ano de 1942, possuia o Estado 12.721 unidades escolares. Funcionaram nesse ano 739 grupos escolares.

Em 1943, foram criadas 309 escolas e 251 classes em grupos escolares, num total de 560 unidades. $\mathrm{O}$ número de grupos escolares criados foi de 2. No fim do ano de 1943 , possuia o Estado 13.210 unidades Funcionaram nesse ano 737 grupos escolares.

Foram criados, até maio do corrente ano, 34 grupos escolares, sendo 6 na capital. Em igual período, foram localizadas 38 escolas isoladas e criadas 175 classes em grupos escolares, num total de 213 .

Até o presente, existem, no Estado, 771 grupos escolares, sendo 104 na capital e 667 no interior. O número de unidades, atualmente, é de 13.405 .

A disseminação de escolas, compreendidas como tais, isoladas e agrupadas, está ligada intimamente com o prédio escolar. Não é possível o bom ensino sem o prédio adequado, por mais esforçado e capaz que seja o professor, como é o nosso.

Cerca de 40 prédios destinados a grupos escolares já foram concluídos; mui- tos outros o serão e, para esse fim, o Interventor Federal, Sr. Fernando Costa, pelo decreto-lei n. ${ }^{\circ} 13.787$, de 31-12-1943, abriu um crédito de Cruzeiros 60.000.000,00 (sessenta milhões de cruzeiros), cuja aplicação se fará por intermédio da Comissão constituída pelo mesmo decreto e já em plena atividade.

Cr\$ 12.000.000,00 (doze milhões de cruzeiros) deverão ser invertidos anualmente na construção de prédios escolares; é interessante assinalar que dessa importância, Cr\$ 4.000.000,00 (quatro milhões de cruzeiros) deverão ser aplicados na construção de prédios de escolas isoladas comuns ou tipicamente rurais. Em futuro próximo, os nossos professores, particularmente da zona rural, terão a sede de sua escola condignamen-te instalada e com residência ao lado, dispondo do conforto mínimo indispensável e que bem merecem.

Em 1941, o total das verbas destinadas ao ensino primário atingiu a Cr\$ 101.543.547,90; no ano de 1944, o total dessas verbas atinge à elevada cifra de Cr\$ 131.136.949,00, tendo sido, com isso, plenamente satisfeitos os compromissos assumidos no Convênio Nacional do Ensino Primário, ratificado pelo Governo Federal, pelo Decreto-lei n. ${ }^{\circ}$ 5.293, de $1 .^{\circ}$ de março de 1943, e pelo Govêr-no do Estado, pelo Decreto-lei n. ${ }^{\circ} 13.440$, de 30 de junho do mesmo ano.

Assistência escolar - A par do desenvolvimento e melhoramento de seu aparelhamento escolar, preocupou-se, também o Governo do Estado em proporcionar aos escolares uma assistência mais constante.

Assim é que, pelo Decreto 13.444. de 2 de junho de 1943, estendeu o serviço de saúde escolar às unidades primárias do interior. Através desse serviço, educadoras sanitárias, com exercício nas Delegacias Regionais do Ensino, executam em cada unidade escolar traba- 
lhos de defesa da saúde dos alunos dos nossos grupos escolares e escolas isoladas, em colaboração com os Centros de Saúde.

No período de junho de 1941, a esta parte, 32 gabinetes dentários foram instalados nos grupos escolares do Estado, estando hoje em funcionamento 173 clínicas escolares no Estado.

Ensino Secundário - Pela reforma do ensino secundário, levada a efeito pelo Decreto-lei federal n. ${ }^{\circ} 4.244$, de 9-4-1942, o ensino secundário é ministrado em 2 ciclos, isto é, em ginásios e colégios. O Governo atual, em conformidade com essa lei, já criou 22 colégios e mantém 21 ginásios.

Estão atualmente em andamento diversos projetos de criação de outros ginásios no interior do Estado.

De acordo com o concurso realizado ultimamente vão ter provimento regular e efetivo, mais de 500 cadeiras que se achavam providas interinamente, norma-lízartdo-se dessa forma a situação de centenas de professores.

O orçamento de 1941 consignava a verba de Cr\$19.890.199,20, para aten-dar aos encargos relativos ao ensino secundário.

No orçamento do corrente exercício, essa verba subiu a Cr\$ 25.991.005,10, O que demonstra eloqüentemente $o$ interesse que tem tido o Governo pela educação secundária de nossa mocidade.

Conta o Estado, atualmente, para ensino secundário, com os seguintes estabelecimentos : 22 colégios, 21 ginásios e 18 escolas normais oficiais. Nestas, como se sabe, é, também, ministrado o ensino secundário.

O Ensino Profissional - E' bem conhecida a organização do nosso ensino técnicoprofissional, que vem sendo ministrado eficientemente, através de 19 estabelecimentos oficiais, além dos municipais e particulares e, também, por intermédio dos Núcleos de Ensino Profissional

A Escola Técnica "Getúlio Vargas", desta Capital, criada pelo Decreto n. ${ }^{\circ} 13.125$, de 1512-1942 é o estabelecimento de maior vulto existente na organização do ensino profissional do Estado.

Nela transformou-se, sob novos e mais amplos moldes e em nível superior, o tradicional Instituto Profissional Masculino, instalado há mais de 30 anos, nesta Capital.

Para sua adequada instalação, está o Governo construindo no mesmo local em que se acha, prédio amplo, a fim de que possam desenvolver-se suas atividades .

Em consequiência da vigência das leis federais, já se acha concluído e em andamento o projeto de enquadramento dos estabelecimentos de ensino profissional, em concordância com o Decreto-lei federal $\mathrm{n}^{\circ}$ 4.073, de 30-1-1942.

Fêz-se a ampliação das terras da Escola Profissional Agrícola de Pinhal; a construção de novos edifícios para inter-nato de alunos nas Escolas de Pinhal, São Manuel e Jacarei. Além dessas, outras construções foram determinadas, a saber construção de oficinas de electrotécnica e mecânica, na Escola de Santos; construção de pavilhão de fundição e reforma geral do prédio central da Escola de Rio Claro; ampliação das oficinas e reforma do prédio da Escola de Ribeirão Preto; construção do prédio central da Escola de Botucatu; construção do prédio c instalação das oficinas da Escola de Jaú.

Ao S.E.N.A.I., Serviço Nacional de Aprendizagem Industrial, vem o Governo do Estado, por intermédio de elementos da Superintendência do Ensino Profissional, prestando seu apoio e colaboração com a designação de vários técnicos e ou- 
tros elementos adextrados nas escolas que atualmente servem naquela importante organização.

Com o Ensino Profissional despendia o Estado, em 1941, Cr\$ 9.394.540,00. No corrente ano, essa cifra eleva-se a $\mathrm{Cr} \$$ $14.640 .845,70$.

Colônias de Ferias, Parques Infantis, Escolas de Aplicação ao Ar Livre - $\mathrm{O}$ serviço de Colônias de Férias passou por um impulso apreciável com atividades das mais auspiciosas.

Assim é que além da Colônia Marítima Infantil " Álvaro Guião ", em Santos, que foi reaberta, instalou-se a Colônia Vale do Paraíba, em Pindamonhan-gaba. Também foi localizada pelo Departamento de Educação Física em Campos do Jordão, a Colônia da Serra da Mantiqueira. Os parques infantis atravessam uma fase promissora. Sob a orientação do Departamento de Educação Física, já se encontram instalados 4 parques no interior c outros muitos estarão em condições de funcionar dentro em breve, mantidos pelas Prefeituras.

Mantém o Departamento de Educação Física, com excelentes resultados, escolas de aplicação ao ar livre, nas quais, além do ensino pré-primário e primário, é ministrada educação física às crianças, por professoras especializadas; cen- tro de educação física instalado nas dependências do Estádio Municipal do Pacaembu, que vem proporcionando ao público, a prática racional da educação física com a assistência permanente de médicos e de instrutores especializados.

Desde 1941, o Departamento de Educação Física passou a inspecionar e orientar a prática da educação física em todos os estabelecimentos de ensino secundário e normal oficiais. Nos grupos escolares, é ministrado o ensino de educação física às crianças, por intermédio de competentes professoras, cujos serviços já se vão estendendo-se às cidades do interior.

Como se vê, o Governo do Estado vem cuidando com especial interesse, da educação física das nossas crianças e jovens que freqüentam as escolas e, também, dos homens, em geral, bem certo do papel que representa a cultura física na formação do nossa raça".

\section{RIO DE JANEIRO}

O Departamento de Educação iniciou a realização, em caráter experimental, de " missões culturais". Várias dessas missões já percorreram os municípios de Maricá, Saquarema, Araruama, São Pedro da Aldeia e Cabo Frio. No mês de julho, trabalho semelhante será feito nos municípios de Itaguaí, Mangaratiba, Angra dos Reis e Parati.

\section{INFORMAÇÃO DO ESTRANGEIRO}

\section{ARGENTINA}

Segundo informações do Conselho Nacional de Educação da República Argentina, cuja população é de 13 milhões de habitantes, estavam matriculados nesse país no ano passado em escolas públicas e particulares 2.005.731 alunos primários, que correspondem a $15,42 \%$ do total de habitantes.
Para esses alunos havia 14.060 escolas, com 76.368 professores.

As crianças em idade escolar que recebiam instrução, eram 1.929.818 matriculados em 13.615 escolas, que contavam 73.754 professores. Os adultos que freqüentavam escolas primárias eram 75.913 que dispunham de 445 escolas especiais, com 2.614 professores. 